\title{
O que Richard Feynman tem a nos ensinar sobre natureza da ciência? ${ }^{+*}$
}

José Guilherme Licio ${ }^{1}$

Mestrando do Programa de Pós-Graduação Interunidades

em Ensino de Ciências - Universidade de São Paulo

Cibelle Celestino Silva ${ }^{1}$

Universidade de São Paulo

São Carlos - SP

\section{Resumo}

Em 11 de maio de 2018, comemorou-se 100 anos do nascimento do físico estadunidense Richard Phillips Feynman, vencedor do Prêmio Nobel de Física em 1965. Além de suas contribuições na área cientifica, Feynman é conhecido por suas produções didáticas e de divulgação cientifica. Neste artigo, apoiados pela Análise Textual Discursiva e pela abordagem de Ciência Integral, fazemos uma análise crítica da palestra ministrada por Feynman quando recebeu o Prêmio Nobel, explicitando informações e conhecimentos que fomentam uma visão contextualizada e humanizada do físico e seu trabalho, bem como um afastamento da visão anedótica construída sobre o personagem. Pela análise depreendemos diversas questões que ilustram aspectos da natureza da ciência relevantes na educação científica, tais como a importância dos erros conceituais cometidos pelo cientista, questões que motivam cientistas, formas como um cientista de prestígio constrói uma versão particular de seu trabalho cientifico e posicionamentos polêmicos. A partir de estudos deste tipo, é possível promover visões mais críticas e bem informadas sobre a ciência tanto para professores, estudantes, cientistas e público leigo.

Palavras-chave: Richard Feynman; Prêmio Nobel; Ensino de Física; Análise Textual Discursiva; História da Ciência.

\footnotetext{
${ }^{+}$What can Richard Feynman teach us about the nature of science?

* Recebido: junho de 2019. Aceito: fevereiro de 2020.

${ }^{1}$ E-mails: jguilherme137@gmail.com; cibelle@ifsc.usp.br
} 


\begin{abstract}
On May 11, 2018, it was celebrated the $100^{\text {th }}$ anniversary of the American physicist Richard Phillips Feynman, winner of the 1965 Nobel Prize in Physics. Besides his contributions to the scientific field, Feynman is known for his activities on teaching and scientific dissemination. In this paper, supported by the textual discursive analysis and the whole science approach to nature of science, we make a critical analysis of the lecture given by Feynman when he received the Nobel Prize. We explore aspects of the conference fostering a contextualized and humanized views on the physicist and his work. In the analysis, we discuss several issues illustrating elements of the nature of science that are relevant to science education, such as the importance of conceptual errors, motivation, controversial positions, and how a prestigious scientist builds a particular version of his scientific work. From studies of this type, it is possible to promote more critical and well-informed views about science for teachers, students, scientists, and the lay public.
\end{abstract}

Keywords: Richard Feynman; Nobel Prize; Physics Teaching; Textualdiscursive Analyses; History of Science.

\title{
I. Introdução
}

Pesquisas em ensino de ciências têm apontado para a importância de discutir aspectos relacionados à natureza da ciência em diversos níveis de ensino (CACHAPUZ; GILPÉREZ, et al., 2005; FORATO; PIETROCOLA; MARTINS, 2011; MARTINS, 2015; SANTOS; MORTIMER, 2019) sob diferentes enfoques, tais como abordagem CTSA (ROBERTS, 1988; SANTOS; MORTIMER, 2000) e abordagem histórica (MATTHEWS, 1994). A análise detalhada e crítica de um episódio histórico permite um entendimento mais informado a respeito de como a ciência funciona, sobre os aspectos humanos dos personagens envolvidos e das relações que existem, por exemplo, entre cientistas, sociedade e política. Para promover um entendimento mais rico e informado acerca das ciências, é importante o apoio de estudos históricos contextualizados sobre tais personagens, evitando o endeusamento e o extremo oposto que seria a relativização completa da importância de cientistas icônicos.

Richard Phillips Feynman (1918-1988), um dos vencedores do Prêmio Nobel de Física em 1965, é um caso emblemático, pois as autobiografias e materiais de divulgação a ele relacionados ressaltam seus chistes, excentricidades, atitudes informais, e gostos pessoais ${ }^{2}$.

\footnotetext{
${ }^{2}$ Além das autobiografias que detalharemos melhor em seções posteriores, podemos ressaltar, por exemplo, que Feynman se tornou um personagem tão emblemático para a visão de física que até mesmo uma história em quadrinhos foi feita a seu respeito (OTTAVIANI e MYRICK, 2011), em que o cientista é retratado como alguns
} 
Essas passagens, embora curiosas, fomentam visões rasas da figura histórica de Feynman, que de maneira alguma pode ser a elas resumida. Ele, como qualquer cientista, também é fruto de sua época, contexto histórico-social e valores pessoais.

Neste artigo, apoiados pela Análise Textual Discursiva e pela abordagem de Ciência Integral, fazemos uma análise crítica da palestra ministrada por Feynman quando recebeu o Prêmio Nobel, explicitando informações e conhecimentos que fomentam uma visão contextualizada e humanizada do físico e seu trabalho, bem como um afastamento da visão anedótica construída sobre o personagem.

\section{Richard Feynman: origens}

Richard Phillips Feynman nasceu em Nova Iorque, em 11 de maio de 1918, tendo falecido em Los Angeles em 15 de fevereiro de $1988^{3}$. Crescendo em um ambiente intelectualizado, Feynman foi incentivado a se interessar por temas científicos, ler enciclopédias e também se divertir com brincadeiras envolvendo matemática e raciocínio lógico. O interesse por física vem desde sua infância, assim como suas preocupações em explicar os conceitos de forma acessível ao maior número de pessoas e também seu desacordo com alguns tipos de figuras autoritárias nas ciências.

Seu pai, Melville Arthur Feynman, chegou aos Estados Unidos como imigrante de Minsk, Belarus, em 1895. A ascendência judaica teve implicações na formação e no interesse de Richard Feynman pelas ciências, posto que seu avô, incorporando ideias defendidas por judeus da região da qual era oriundo, pertencia a um grupo de pensadores orientados ao racionalismo científico ${ }^{4}$. Segundo o próprio Feynman (MEHRA, 1994, p. 2), seu interesse sobre

super-heróis. Há obras que apresentam o físico ressaltando passagens anedóticas e fazendo pouca ou nenhuma crítica a respeito do contexto em que viveu Feynman ou suas motivações para ser cientista (MLODINOW, 2011; GLEICK, 1993). O documentário de 1993 “The Best Mind Since Einstein”, que se traduz como "A melhor mente desde Einstein", produzido pela produtora PBS Nova foca inclusive em comentários de Feynman a respeito da existência de discos voadores, que pouco contribuem para um entendimento crítico das ideias do cientista e apenas reforçam as características excêntricas da persona de Feynman. Em 1996, foi feito o filme "Infinity - Um Amor Sem Limites" a respeito de passagens da vida do cientista, também trazendo nenhuma crítica ou visão menos estereotipada sobre Feynman.

${ }^{3}$ Algumas fontes popularmente utilizadas para se conhecer sobre o cientista são suas autobiografias $O$ Senhor está brincando, Sr. Feynman? (FEYNMAN, 2006) e Nem sempre a brincar, Sr. Feynman: novos elementos para o retrato de um físico enquanto homem (FEYNMAN e LEIGHTON, 1988), além de obras de divulgação científica. Para que possamos ter uma visão crítica a respeito de sua trajetória recorremos também a fontes secundárias tais como os livros The Beat of a Different Drum, de Jagdish Mehra (biográfico sobre Feynman), QED and the men who made it, de S. S. Schweber (a respeito do contexto histórico do desenvolvimento da eletrodinâmica quântica) e Quantum Generations: A history of physics in the twentieth century, de Helge Kragh (que traz estudos históricos sobre o contexto da física no século XX).

Por "racionalismo" aqui se entende a visão epistemológica de que todo conhecimento é oriundo da razão, toda construção do conhecimento deve partir da razão e os testes deste conhecimento devem ser pautados pela razão. Nessa visão, a razão consegue construir conhecimentos que vão além daqueles que são construídos apenas com os sentidos ou com a experimentação. Com isso, os racionalistas são geralmente confrontados com aqueles que adotam posturas empiristas em relação ao conhecimento científico (BLANSHARD, 2016; BLACKBURN, 1996). 
padrões foi despertado desde muito cedo por influência paterna. Esse tipo de interesse ecoaria nos tipos de desenvolvimentos científicos feitos por Feynman ao longo de sua carreira. Sua mãe, Lucille Phillips teve educação formal e vivia num ambiente econômica e intelectualmente privilegiado, sendo pouco lembrada pelo cientista no que diz respeito aos seus interesses científicos.

O jovem Feynman graduou-se em 1939 no Massaschussets Institute of Technology (MIT), uma das universidades mais consagradas dos EUA. O período de Feynman na graduação foi essencial para que ele se atentasse aos problemas que existiam na formulação clássica da eletrodinâmica. Desde então passou a se interessar pelo tema, que, em 1965, culminaria com seu reconhecimento pelo Prêmio Nobel.

Há, por vezes, a ideia de que grandes cientistas só foram grandiosos devido a uma suposta genialidade inata. Vemos, no caso de Feynman, um claro exemplo de que a "genialidade" não é algo inato, mas uma construção que ocorre ao longo de muitos anos e depende do contexto social vivido pelo cientista, bem como de interesses específicos acerca de que visões sobre ciências são desejadas para a sociedade. O que depreendemos dos primeiros anos de sua vida é que o físico Feynman não surgiu num vácuo social. É evidente que Feynman teve oportunidades e privilégios para dedicar-se a um trabalho intelectual, e pôde escolher alguns dos caminhos que seguiu em sua vida acadêmica.

\section{O Prêmio Nobel de Física de 1965 em contexto}

Tanto entre o público leigo quanto entre cientistas, o Prêmio Nobel, desde sua instituição em 1901, é considerado o maior reconhecimento que um profissional da área científica pode receber. O processo de escolha dos laureados é complexo ${ }^{5}$. Ao longo do ano, cientistas eminentes (entre os quais estão membros da Academia Sueca de Ciências e ex-laureados), indicam nomes para concorrer ao Prêmio. São realizadas assembleias e plenárias para considerar as motivações de algumas das indicações realizadas. Após um longo processo, o vencedor é declarado (KRAGH, 2002).

Em uma cerimônia anual, na época do aniversário da morte de Alfred Nobel, os laureados recebem das mãos do rei da Suécia a medalha do Prêmio. Na ocasião, os laureados proferem palestras oficiais sobre os trabalhos realizados ${ }^{6}$. Ao proferir um discurso de tamanha importância, os cientistas têm, como público alvo, não somente seus pares, mas a posteridade, dada a importância mundial da cerimônia. Em suas falas, os cientistas distorcem, exageram,

\footnotetext{
${ }^{5}$ Para informações mais detalhadas a respeito do processo de escolha dos laureados veja (LICIO, 2018).

${ }^{6}$ As transcrições oficiais dessas palestras estão disponíveis gratuitamente no website do Prêmio. As palestras são proferidas na língua vernácula do ganhador ou ganhadora. No website, a maior parte das palestras é disponibilizada somente em inglês, segundo uma tradução oficial. Além desses materiais, também estão disponíveis os discursos proferidos pelos cientistas nos jantares, as entrevistas e também o discurso de apresentação do Prêmio, sempre realizado por algum membro eminente da Academia. Nos casos das premiações mais recentes, os vídeos das palestras também estão disponíveis.
} 
omitem e também racionalizam a respeito de como ocorreu o processo de pesquisa e descoberta. Não costuma ser do interesse do comunicador dar detalhes minuciosos sobre seus erros, novas tentativas, conflitos e dúvidas. Então o que se costuma apresentar é uma versão pasteurizada da história, que enfatiza o que o cientista intimamente considera mais importante ou digno de ser publicizado. Em outras palavras, numa palestra deste tipo, há sempre a possibilidade de enxergarmos um pouco das convicções pessoais dos cientistas, seus valores, suas crenças e suas visões de mundo, para além de um mero registro de como teria sido o desenvolvimento científico que culminou na premiação.

Em 1965, o Prêmio Nobel de Física foi dividido entre três físicos. Além de Richard Feynman, o japonês Sin-Itiro Tomonaga (1906-1979) e o estadunidense Julian Schwinger (1918-1994) foram laureados "por seus trabalhos fundamentais em eletrodinâmica quântica, com grandes consequências na física de partículas elementares" (NOBELPRIZE.ORG, 2019).

Os trabalhos que culminaram no Prêmio foram desenvolvidos a partir de 1947, 18 anos antes da premiação ${ }^{7}$. Esses trabalhos têm suas raízes no começo do século XX, por volta de 1928, com a teoria desenvolvida pelo cientista Paul Dirac (1902-1984) sobre a estrutura fina do átomo de hidrogênio. Essa primeira geração do que passou a ser chamado de eletrodinâmica quântica ( $Q E D$, do nome em inglês) concordava parcialmente com algumas evidências experimentais conhecidas à época. No entanto, havia discrepâncias entre observações e expectativas teóricas, que demoraram algumas décadas até serem solucionados, exigindo reformulações teóricas. A resolução desses problemas marcou uma importante mudança na maneira de se entender a interação das partículas fundamentais ${ }^{8}$.

A teoria de Schwinger ajudou a construir uma eletrodinâmica quântica auto consistente que, além de concordar com as observações experimentais, possibilitou a descrição de qualquer sistema que contivesse elétrons, pósitrons e fótons na presença de um campo coulombiano externo. Na mesma época, Sin-Itiro Tomonaga, juntamente com seu grupo no Japão, desenvolveu independentemente uma teoria similar que também utilizava as mesmas técnicas e almejava os mesmos objetivos. Em 1948, Tomonaga e seus colaboradores publicaram na Physical Review um sumário de seus trabalhos (TOMONAGA; OPPENHEIMER, 1948).

Richard Feynman entra em cena ao apresentar o que passou a ser chamada de uma terceira versão da QED. Feynman concluiu seu doutorado em 1942, sob orientação do professor John Archibald Wheeler (1911-2008) ${ }^{9}$. Seu primeiro trabalho científico lidava com

\footnotetext{
${ }^{7}$ Essa informação deve ser considerada com cautela. O interesse de Feynman sobre problemas de eletrodinâmica clássica, segundo o cientista, foi despertado quando ele ainda estava na graduação (concluída em 1939). O ano de 1947 marca os primeiros estudos formais que passou a desenvolver a fim de reformular a eletrodinâmica conhecida na época. De qualquer forma, o importante nessas datas é notar que Feynman começou a estudar o que lhe rendeu o Prêmio Nobel muito tempo antes de ser premiado.

${ }^{8}$ Para maiores informações acerca das discrepâncias entre a teoria de Dirac e os resultados experimentais disponíveis veja a seção 6.4 de (LICIO, 2018).

${ }^{9}$ O professor Wheeler foi importante para alguns dos caminhos acadêmicos que Feynman tomou ao longo de sua carreira. Wheeler era um cientista reconhecido. Uma de suas características era a de questionar os chamados
} 
uma nova formulação da eletrodinâmica clássica baseada na interação direta entre partículas. A ideia original de Feynman era resolver os problemas das divergências na teoria clássica, crendo que os problemas também desapareceriam na versão quântica. Embora isso não tenha acontecido, esses trabalhos propiciaram familiaridade para Feynman com a teoria que estava sendo trabalhada e o inspiraram a formular a mecânica quântica em uma visão espaçotemporal, em termos de amplitudes de trajetórias. Em 1947, Feynman começou a desenvolver sua versão da QED baseada na abordagem de integrais de trajetórias (FEYNMAN, 1948; FEYNMAN, 1951). Em 1948, havia duas versões da QED renormalizada: a de Schwinger/Tomonaga e a de Feynman. Ambas geravam os mesmos resultados, mas não concordavam entre si. A equivalência entre as formulações foi demonstrada em 1949 pelo trabalho de Freeman Dyson (1923-2020), um matemático inglês de 25 anos na época (DYSON, 1948). Em 1949, ele derivou a teoria de Feynman de sua própria maneira, formulando-a pela primeira vez como teoria de campo e provando matematicamente que era equivalente à teoria de Schwinger (DYSON, 1949). Com essa síntese, a nova QED renormalizada estava completa.

A teoria construída não era de fato uma teoria nova, no sentido de que ela não negava nem substituía a teoria antiga. Em vez disso, ela pode ser vista como uma versão melhorada do que se fazia antes da Segunda Guerra mundial. Os físicos mais jovens da época tinham essa continuidade como objetivo, em contraste com as atitudes revolucionárias da geração anterior (representada por cientistas como Dirac, Bohr e Heisenberg), em que se evidenciavam grandes rompimentos com as formulações anteriores (KRAGH, 2002, p. 336). Feynman, Schwinger, Tomonaga e Dyson tinham uma postura mais pragmática ao considerarem tanto a mecânica quântica quanto a teoria da relatividade como pilares fundamentais da física, usando-as para o desenvolvimento de teorias novas como as versões de QED (KRAGH, 2002; SCHWEBER, 1994).

\section{Com que óculos ler?}

Nesta seção esclareceremos quais são nossos objetivos, embasamento teórico e metodologia de análise empregados na análise da palestra de Richard Feynman. Nosso objetivo é explicitar como Feynman enxergava o trabalho científico ${ }^{10}$. Por isso interpretamos as palavras de Feynman à luz de conhecimentos atuais sobre natureza da ciência.

\footnotetext{
"fundamentos da mecânica quântica", isto é, as bases conceituais sobre as quais se apoia essa parte da física. Outros cientistas relevantes tiveram orientação acadêmica de Wheeler, inclusive o brasileiro Jayme Tiomno, que, além das contribuições teóricas, teve estreitas relações com as viagens de Feynman ao Brasil (BASSALO; JUNIOR, 2003).

${ }^{10} \mathrm{O}$ que buscamos não são as minúcias técnicas apresentadas por Feynman sobre seus trabalhos em eletrodinâmica quântica. O que Feynman diz sobre aspectos técnicos é secundário em sua apresentação, segundo o que ele mesmo afirma logo no início de sua palestra, já que os outros dois laureados daquele ano já falariam com mais detalhes a respeito da teoria pela qual foram reconhecidos. Além disso, hoje em dia a parte técnica, tanto em níveis básicos quanto nos mais avançados, é disponível por meio de livros-textos tradicionais de mecânica quântica (SAKURAI, 1967; SHANKAR, 1994), eletrodinâmica (JACKSON, 1999), física de partículas
} 
Determinar aspectos de natureza da ciência na leitura de fontes históricas ou análise de episódios históricos não é uma tarefa a ser executada univocamente, já que há diversos enfoques para a natureza da ciência propostos desde pelo menos os anos 1960 (ROBINSON, 1965). A abordagem adotada para ler a palestra de Feynman é a chamada Ciência Integral (Whole Science, em inglês), proposta por Douglas Allchin (ALLCHIN, 2013). Tal abordagem permite compreender a complexidade dos processos de produção e validação do fazer científico ao propor as "dimensões de confiabilidade" que exploram aspectos experimentais, teóricos e contextuais que podem ser classificados de acordo com três dimensões interligadas e não excludentes:

- Dimensão observacional: Considera aspectos referentes aos experimentos, às medidas e aos instrumentos usados pelos cientistas. Questões como robustez dos dados empíricos, precisão das medições e validação de novos instrumentos de medição encaixam-se nessa dimensão.

- Dimensão conceitual: A parte cognitiva do fazer científico é realçada nesta dimensão. A ela pertencem padrões de raciocínio dos cientistas, dimensões históricas influentes sobre um trabalho científico, papel dos erros e aproximações, usos de metáforas e crenças epistemológicas dos cientistas.

- Dimensão sociocultural: Nesta, são englobados aspectos que dizem respeito à interação entre cientistas e instituições, vieses ideológicos dos cientistas, papel da economia e financiamento de projetos científicos e natureza das comunicações dos cientistas - tanto com seus pares quanto com o público geral.

Essas dimensões não pretendem esgotar os aspectos da natureza da ciência, portanto não são limitantes ou normativas; elas se apresentam como um instrumento que organiza a análise.

Utilizamos a Análise Textual Discursiva (ATD), proposta por Maria do Carmo Galiazzi e Roque Moraes (MORAES; GALIAZZI, 2016) como metodologia de análise. De acordo com os autores, a ATD traz aspectos que remetem à Análise de Conteúdo, especialmente à proposta por Laurence Bardin (BARDIN, 1977) e também aspectos que a aproxima da Análise do Discurso. Em suma, a ATD é uma metodologia que investiga tanto informações presentes explicitamente no objeto de estudo, quanto informações implícitas, como as relacionadas à natureza da ciência. Segundo a metodologia da ATD, a análise se divide em seleção do material, unitarização, categorização, descrição e interpretação. Essas etapas não precisam ocorrer de forma sequencial ou linear. O material analisado contempla a transcrição da palestra de Feynman e fontes secundárias. A unitarização é representada pela numeração dos parágrafos e pela seleção de trechos representativos. A categorização é apresentada como uma separação em diferentes tópicos levantados pelo cientista em sua comunicação e que são de nosso inte-

(GRIFFITHS, 2008) e especialmente pelos artigos publicados pelo próprio Feynman em periódicos científicos e livros sobre sua pesquisa (FEYNMAN, 1985; BROWN, 2000). 
resse. A descrição contextualiza os trechos salientados. Na fase da interpretação, relacionamos nossa análise com a abordagem de Ciência Integral, explicitando quais dimensões de confiabilidade podem ser exploradas no material.

Mesmo que Feynman tivesse a pretensão de descrever factualmente como seus trabalhos foram realizados, ainda assim haveria vieses inerentes na construção de qualquer narrativa. Quando estudamos os relatos de um cientista sobre suas próprias realizações, é necessário termos cuidado em sempre nos lembrarmos que aquela narrativa é uma construção, na qual alguns detalhes podem estar sendo exagerados, omitidos ou mesmo inventados. O narrador geralmente busca uma descrição racionalizada sobre os acontecimentos, suprimindo ou mesmo exagerando seus erros, dúvidas e angústias (KRAGH, 1987). Essa tentativa de racionalização com a intenção de se passar uma visão específica a respeito de como um trabalho científico foi construído relaciona-se, no âmbito da Ciência Integral, com a dimensão de confiabilidade sociocultural da natureza da ciência, uma vez que o cientista relata a respeito de como seu trabalho influencia e é influenciado pela cultura científica de seu tempo.

Na prática, nem sempre o trabalho científico desenvolve-se de maneira harmônica ou linear. Explicitar o caos que pode ocorrer durante certas etapas de uma pesquisa não é algo trivial, por isso, devemos ser cuidadosos ao lermos narrativas dos próprios cientistas. Apesar disso, mesmo após passadas pelo filtro do cientista, suas narrativas ainda podem fornecer informações importantes. Se depois de todo o processo de organização ainda encontramos pistas de como o cientista enxergava a ciência, isso quer dizer que há grandes possibilidades de que as mensagens remanescentes sejam intencionais. Por isso, uma comunicação oficial, como a palestra do Prêmio Nobel, se por um lado traz dúvidas quanto à factualidade do que é descrito, por outro traz evidências sobre o que o cientista pretendia que fosse entendido.

\section{Análise da Palestra}

Nesta seção analisamos nossa tradução da palestra ministrada por Richard Feynman quando recebeu o Prêmio Nobel de Física em $1965^{11}$, cujo título é "O desenvolvimento da visão espaço-temporal da eletrodinâmica quântica". As categorias construídas a partir da Ciência Integral são: como Feynman viu papel dos erros no desenvolvimento de sua teoria, suas crenças epistemológicas e preferências estéticas a respeito de como deve ser construída uma teoria científica, seu uso de anedotas e, por fim, o machismo presente em trechos de sua fa$1 \mathrm{a}^{12}$.

\footnotetext{
${ }^{11}$ A tradução para a língua portuguesa foi feita por nós. Originalmente, os parágrafos não eram numerados; inserimos a numeração para podermos nos referir a trechos específicos quando apresentarmos nossa análise. Uma tradução independente da nossa foi publicada recentemente em (NOVAES, 2018). O texto original, "The Development of the space-time view of quantum electrodynamics", está disponível gratuitamente no website do Prêmio Nobel.

${ }^{12}$ Tais categorias foram adaptadas do inventório parcial de dimensões de confiabilidade proposto por Allchin (ALLCHIN, 2013).
} 


\section{V.1 Cientistas cometem erros}

Um aspecto que chama atenção ao longo da palestra são os vários momentos em que Feynman fala a respeito dos erros cometidos durante suas pesquisas. É comum que cientistas cometam equívocos até chegarem a uma resposta considerada satisfatória, mas não é tão comum encontrar discursos feitos pelos próprios cientistas abordando francamente esse tipo de situação. Logo no primeiro parágrafo de sua palestra, Feynman diz que tratará de questões que geralmente não têm espaço para serem tratadas em comunicações científicas, por exemplo, os erros e os pontos cegos encontrados durante sua pesquisa:

Nós temos um hábito, ao escrever artigos publicados em periódicos científicos, de
fazer o trabalho parecer o mais finalizado possivel, cobrindo todos os caminhos,
sem nos preocuparmos com os pontos cegos, ou em descrever como tivemos a ideia
errada primeiro, assim por diante. Assim, não há muito espaço para publicar, de
maneira digna, o que você realmente fez em seu trabalho, apesar de que, nos últi-
mos tempos, tem havido algum interesse nesse tipo de coisa. Como ganhar o Prêmio
é algo pessoal, pensei que eu poderia ser perdoado se, nessa situação particular,
pudesse dizer pessoalmente sobre minha relação com a eletrodinâmica quântica, em
vez de discutir o assunto em si de maneira refinada e finalizada. Além do mais, uma
vez que três pessoas ganharam o Prêmio em Física, se todos eles fossem falar sobre
a eletrodinâmica quântica, vocês poderiam ficar entediados com o tema. Então, o
que eu gostaria de dizer hoje é sobre a sequência de eventos, a sequência verdadei-
ra de ideias que ocorreram, pelas quais eu acabei com um problema não resolvido,
pelo qual, em última instância, eu recebi o Prêmio (FEYNMAN, 1965, $1^{\circ}$ parágra-
fo).

Assumir os próprios erros pode ser uma ferramenta retórica útil para que um cientista transmita uma imagem confiável a respeito de como procedeu em sua pesquisa e também ao que se seguirá em sua fala. Alguns autores apontam, por exemplo, que esse recurso foi amplamente utilizado pelo químico Robert Boyle no século XVII, para que a comunicação de seus resultados de pesquisa passasse a imagem de honestidade e franqueza (SHAPIN e SCHAFFER, 1985; GOLINSKI, 1990). Ao mencionar seus erros numa ocasião de tamanha visibilidade mundial como é uma palestra de Prêmio Nobel, Feynman constrói confiabilidade em sua narrativa - afinal, se ele sabe seus erros, é sinal de que ele tem uma atitude crítica sobre o próprio trabalho, reconhecendo possíveis limitações de suas construções.

No $9^{\circ}$ parágrafo, ele menciona um de seus erros:

Então eu entrei na pós-graduação. Em algum ponto aprendi o que estava errado com a ideia de que um elétron não atua sobre si mesmo. Quando você acelera um elétron, ele irradia energia e você deve fazer trabalho extra para explicar essa energia. A força extra contra a qual esse trabalho é realizado é chamada de força de resistência de radiação. A origem dessa força extra era identificada, naqueles dias, seguindo Lorentz, como a ação do elétron. O primeiro termo dessa ação, do elétron sobre si mesmo, dava um tipo de inércia (que não era relativisticamente sa- 
tisfatória). Mas esse termo inercial era infinito para uma carga pontual. Ainda assim, o próximo termo na sequência dava uma taxa de perda, que para uma carga pontual concorda exatamente com a taxa que você encontra calculando quanta energia é irradiada. Então, a força de resistência de radiação, que é absolutamente necessária para a conservação da energia, desapareceria se eu dissesse que a car-

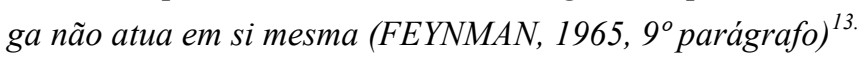

No $10^{\circ}$ parágrafo, Feynman relata a importância que seu orientador à época, John Wheeler, teve ao apontar erros que ele mesmo não conseguira identificar.

Portanto eu aprendi, no tempo em que eu estava na pós-graduação, a falha evidentemente óbvia da minha própria teoria (...). Então, um dia, quando eu estava trabalhando para o Professor Wheeler e não conseguia mais resolver o problema que ele havia me dado, eu pensei de novo sobre isso e calculei o seguinte: suponha que eu tenha duas cargas - eu chacoalho a primeira, a qual eu penso como uma fonte, e isso faz com que a segunda chacoalhe, mas o chacoalhar da segunda produz um efeito de volta na fonte. E então eu calculei quanto era esse efeito sobre a primeira carga, esperando que isso resultasse na força de resistência de radiação. Não deu certo, claro, mas eu contei ao Professor Wheeler minhas ideias. Ele disse: sim, mas a resposta que você consegue para as duas cargas que você mencionou vai depender, infelizmente, da carga e da massa da segunda carga, variando inversamente com o quadrado da distância $R$ entre as cargas, enquanto que a força de resistência de radiação não depende dessas grandezas. Eu pensei que com certeza ele havia computado isso por si mesmo, mas agora, tendo me tornado professor, eu sei que uma pessoa pode ser sábia o bastante para ver imediatamente o que um estudante de pósgraduação demora semanas para desenvolver (...) (FEYNMAN, 1965, 10 Parágrafo).

No $41^{\circ}$ parágrafo, após contar sobre seus diversos avanços teóricos na quantização da eletrodinâmica, Feynman comenta que sentia que havia cometido um erro, mas não conseguia identificar exatamente qual era, evidenciando o papel da intuição na ciência. A ciência, portanto, não é uma construção totalmente pautada pela razão.

Também foi fácil adivinhar como modificar a eletrodinâmica, se qualquer um quisesse fazê-lo. Eu apenas mudei o delta para uma função $f$, assim como eu faria para o caso clássico. Então era bem fácil, bem simples. Para descrever a velha teoria de ondas atrasadas sem mencionar explicitamente os campos, eu teria que escrever probabilidades, não apenas amplitudes. Eu teria que quadrar minhas amplitudes $e$ isso envolveria integrais duplas de trajetória, em que existem dois $S$, assim por diante. Ainda assim, quando eu trabalhei muitos desses casos e estudei formas diferentes e condições de contorno diferentes, eu tive um tipo de sensação engraçada de que as coisas não estavam exatamente certas. Eu não conseguia identificar claramente qual era a dificuldade. Em um dos curtos periodos nos quais eu imaginei

\footnotetext{
${ }^{13}$ Todos os grifos em citações neste artigo são dos autores.
} 
que teria de deixar isso de lado por um tempo, publiquei uma tese e recebi meu Ph.D. (FEYNMAN, 1965, $41^{\circ}$ parágrafo).

Foi no contexto da Segunda Guerra Mundial, enquanto trabalhava no Projeto Manhattan, que finalmente Feynman entendeu o que tinha feito de errado.

Durante a Guerra, eu não tive tempo de trabalhar nesses assuntos muito extensivamente, mas fiquei pensando sobre isso enquanto estava no ônibus e assim por diante. Com alguns pedaços de papel me esforcei para trabalhar isso e descobri que de fato havia algo errado, algo terrivelmente errado. Descobri que se alguém generalizar a ação a partir das boas formas lagrangianas (2) para as formas (1) ${ }^{14}$, então as quantidades que eu defini como energia e tal, seriam complexas. Os valores de energia de estados estacionários não seriam reais e as probabilidades de eventos não somariam 100\%. Isto é, se você tomar a probabilidade de que isso vai acontecer, de que aquilo vai acontecer e de que tudo o que você imaginar vai acontecer, a soma não seria 1 (FEYNMAN, 1965, $42^{\circ}$ parágrafo).

Esse problema motivou intensos estudos na eletrodinâmica quântica, sendo que o próprio Feynman confessou não ter conseguido chegar a uma solução satisfatória para ele:

Então sonhava que, se fosse esperto, eu poderia encontrar uma fórmula para a amplitude de uma trajetória, que fosse maravilhosa e simples para três dimensões de espaço; e uma de tempo, que seria equivalente à Equação de Dirac, para a qual os quadricomponentes, matrizes e todas aquelas outras coisas matemáticas sairiam como uma simples consequência - eu também nunca consegui fazer isso. Mas eu queria mencionar algumas das coisas mal sucedidas pelas quais me esforcei, assim como as coisas que funcionaram (FEYNMAN, 1965, 45 parágrafo).

Feynman aponta mais um erro que cometeu, no $52^{\circ}$ parágrafo. Dessa vez, o erro foi de ordem operacional, envolvendo a divergência da energia de interação do elétron com ele mesmo:

Então voltei para a minha sala e fiquei pensando sobre essa coisa. Fiquei andando em círculos tentando achar o que estava errado, porque eu tinha certeza de que fisicamente tudo precisava dar um resultado finito e eu não conseguia entender por que estava dando infinito. Fiquei mais e mais interessado, quando finalmente percebi que eu precisava aprender como fazer um cálculo. Então, definitivamente, estudei como calcular a auto energia de um elétron, trabalhando pacientemente sobre a terrivel confusão daqueles dias a respeito de estados de energias negativas, con-

\footnotetext{
${ }^{14}$ Por (1), Feynman se refere à fórmula

$A=\Sigma_{i} m_{i} \int\left(\dot{X}_{\mu}^{i} \dot{X}_{\mu}^{i}\right)^{\frac{1}{2}} d \alpha_{i}+\frac{1}{2} \sum_{i j, i \neq j} e_{i} e_{j} \iint \delta\left(I_{i j}^{2}\right) \dot{X}_{\mu}^{i}\left(\alpha_{i}\right) \dot{X}_{\mu}^{j}\left(\alpha_{j}\right) d \alpha_{i} d \alpha_{j}$, onde $_{i j}^{2}=\left[X_{\mu}^{i}\left(\alpha_{i}\right)-X_{\mu}^{j}\left(\alpha_{j}\right)\right]\left[X_{\mu}^{i}\left(\alpha_{i}\right)-\right.$ $\left.X_{\mu}^{j}\left(\alpha_{j}\right)\right]$.

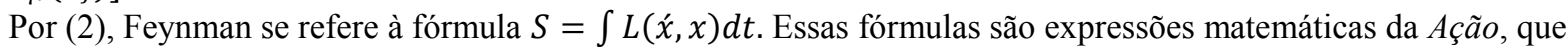
é uma grandeza física relevante em eletrodinâmica quântica.
} 
tribuições longitudinais e assim por diante. Quando eu finalmente descobri como fazer e fiz com as modificações que eu queria sugerir, acabou que [o cálculo] era belamente convergente e finito, como eu esperava que fosse. O Professor [Hans] Bethe e eu nunca fomos capazes de descobrir o que fizemos de errado na lousa, dois meses antes, mas aparentemente nós só tivemos um deslize em algum lugar e nunca conseguimos descobrir onde. No fim, o que eu tinha proposto, se tivéssemos feito sem cometer erros, daria certo e daria uma correção finita. De qualquer forma, isso me forçou a revisar tudo aquilo e me convencer de que fisicamente nada deveria dar errado (FEYNMAN, 1965, 52 parágrafo).

Tanto na teoria antiga, quanto na nova, o cálculo da energia de interação do elétron consigo mesmo gerava uma quantidade infinita e isso era indesejável. Segundo Feynman, a teoria nova não gerava uma divergência, pois o que havia acontecido era um erro de cálculo, deslize que poderia ser cometido por qualquer um até mesmo pelos cientistas considerados geniais.

Na parte final da palestra, Feynman ressalta que grande parte das ideias que teve ao longo de seu trabalho não foram usadas nos resultados finais pelos quais ele foi premiado $\left(61^{\circ}\right.$ parágrafo). Algumas ideias poderiam ser usadas, mas não eram estritamente necessárias. A seguir, no parágrafo 62 , ele diz que muitas de suas ideias até poderiam ser úteis, mas eram apenas re-expressões de conhecimentos já consolidados.

No âmbito da Ciência Integral, temos aqui algumas demonstrações da dimensão conceitual do fazer científico e também da dimensão sociocultural. Se, por um lado, Feynman revela que a narrativa a respeito de como se dá o trabalho científico passa por uma série de filtros até ser divulgada nos periódicos tradicionais, por outro ele também ressalta que o processo de construção do conhecimento não é direto. Pelo contrário, ao mencionar seus erros e suas idas e vindas conceituais até chegar à teoria que lhe rendeu o Prêmio Nobel, Feynman corrobora nosso entendimento de que a visão "pasteurizada" de ciência não reflete a realidade, sendo necessário, para uma visão mais crítica das ciências, levar em consideração os fatores mencionados.

\section{V.2 Influências de crenças pessoais no trabalho de Feynman}

Cientistas têm crenças epistemológicas e preferências estéticas que muitas vezes influenciam o seu trabalho científico (ALLCHIN, 2013). Com Feynman não foi diferente. Em diversos pontos de sua apresentação, ele deixa transparecer algumas de suas crenças epistemológicas, suas visões filosóficas sobre a física e também sobre o que julgava serem as características mais elegantes de uma teoria. 
Ao longo da palestra, Feynman refere-se muitas vezes a pensamentos baseados em sentimentos e crenças pessoais ${ }^{15}$, não necessariamente elaborados de maneira racional. No $7^{\circ}$ parágrafo, Feynman afirma que um plano geral sobre como ele deveria desenvolver seu trabalho baseava-se em resolver um problema clássico, e, então, a solução quântica seguiria automaticamente:

Vejam, então, que o meu plano geral era primeiro resolver o problema clássico, livrar-me das auto-energias ${ }^{16}$ infinitas da teoria clássica e esperar que quando eu fizesse uma teoria quântica disso, tudo estaria bem (FEYNMAN, 1965, 7º parágrafo).

Não há razões para acreditarmos que essa abordagem seja a única possível. Um cientista poderia defender que uma teoria quântica deveria ser construída independentemente da clássica, por exemplo. Mas esse não era o caso de Feynman, que deixa claro em outros pontos da palestra seu esforço para seguir esse programa específico. Seu esforço pode ser um reflexo de atitudes pragmáticas que o físico tinha em relação ao seu trabalho e à sua visão sobre como as ciências devem ser construídas.

Outro aspecto não-epistêmico evidenciado na fala de Feynman diz respeito à simplicidade e à elegância das teorias físicas. Logo no $8^{\circ}$ parágrafo, Feynman relata que "se apaixonou" pela eletrodinâmica devido à ideia de simplicidade e elegância, e, dessa forma, ficou apegado à teoria. Esses fatores são retomados no $18^{\circ}$ parágrafo, em que Feynman diz que toda a eletrodinâmica clássica estava contida numa fórmula simples e que isso a tornava indubitavelmente verdadeira:

Este foi o começo. A ideia parecia tão óbvia e tão elegante para mim que eu me apaixonei por ela. E, assim como se apaixonar por uma mulher, só é possivel se você não sabe muito sobre ela ${ }^{17}$, então você não vê seus defeitos. Esses defeitos só são aparentes mais tarde, mas depois do amor ser tão intenso a ponto de te prender a ela. Então eu me apeguei a essa teoria, apesar de todas as dificuldades, pelo meu entusiasmo juvenil (FEYNMAN, 1965, $8^{\circ}$ parágrafo).

Então toda a eletrodinâmica clássica estava contida nessa fórmula bem simples. Ela tinha boa aparência, e, portanto, era indubitavelmente verdadeira, ao menos para um principiante. [...] Essa então era a solução sobre a qual estávamos esperanço-

\footnotetext{
15 "Crença pessoal” não deve ser entendida como algo pejorativo. O que consideramos como crença pessoal de Feynman, nesse contexto, é, por exemplo, a ideia que ele possuía a respeito de como deveriam ser construídas as teorias científicas, levando em consideração inclusive o caráter de "elegância" das teorias.

${ }^{16}$ Aqui, devemos tomar cuidado com uma armadilha da tradução. O termo original empregado por Feynman para se referir à energia do elétron atuando sobre si mesmo é self-energy, que numa tradução direta significaria auto-energia. No entanto, autoenergia é a tradução usada para o conceito matemático de eigenenergy, que é algo completamente diferente, relacionado com o formalismo da álgebra linear (RILEY; HOBSON; BENCE, 2006). Por isso, ao ler a palestra de Feynman traduzida, devemos tomar cuidado com essa tradução. Autoenergia, aqui, significa a energia do elétron atuando sobre si mesmo.

${ }^{17}$ Este trecho polêmico será retomado numa seção posterior.
} 
sos para nos livrarmos dos infinitos da eletrodinâmica clássica (FEYNMAN, 1965, $18^{\circ}$ parágrafo).

A escolha de uma teoria por sua aparência certamente não se baseia em consensos entre cientistas e tampouco em regras epistemológicas. Uma teoria pode ser considerada correta e condizer com as evidências disponíveis, sem que sejam as mais simples. Da mesma maneira, uma explicação mais simples ou elegante pode estar errada, não sendo, conforme as palavras de Feynman, indubitavelmente verdadeira.

No $27^{\circ}$ parágrafo, Feynman volta ao tema da simplicidade das leis da natureza. Ao relatar que existem muitas maneiras equivalentes de se formular a eletrodinâmica, ele defende que esse aspecto poderia definir simplicidade: se um fato natural pode ser expresso de maneiras diferentes, mas equivalentes entre si, sem que se saiba imediatamente que todas essas maneiras sejam equivalentes, então isso, segundo Feynman, é uma representação da simplicidade das leis naturais. Isso também é uma crença, que pode ser defendida por alguns cientistas e criticada por outros. Não constitui uma regra.

Feynman manifesta sua preferência por teorias mais simples tocando no tema desde pelo menos o $34^{\circ}$ parágrafo, quando diz que, na visão de um de seus colegas de trabalho, os físicos norte-americanos trabalhavam sempre buscando simplicidade nas teorias e que isso não ocorria entre físicos europeus:

O Professor Jehle me mostrou isso, eu li, ele me explicon e eu disse "o que ele quer dizer é que elas são análogas, mas o que análogo significa?". Ele respondeu "vocês, americanos! Sempre tentam achar uma utilidade para tudo!". Eu disse que eu pensei que o que Dirac queria dizer é que ambas eram iguais. "Não", ele explicou, "ele não quer dizer que são iguais". "Bem”, eu disse, "vamos ver o que acontece se eu fizer com que sejam iguais" (FEYNMAN, 1965, 34 parágrafo).

O Professor Jehle ${ }^{18}$ havia apresentado a Feynman a relação proposta por Paul Dirac na qual afirmava que uma certa função era análoga a outra ${ }^{19}$. Feynman não entendia o que essa analogia significava de fato. Portanto, segundo o relato, impôs que as duas funções fossem iguais, adotando uma postura que visava simplificar as escolhas, uma escolha epistemológica bastante comum entre cientistas ${ }^{20}$. Temos neste trecho um indicativo da dimensão sociocultural da natureza da ciência, pois Feynman nos diz que a forma de construir uma teoria científica difere dependendo da cultura da qual se origina o cientista. Especificamente, um físico norte-americano tem um modo de construir teorias diferentes de um físico europeu.

\footnotetext{
${ }^{18}$ Herbert Jehle, físico alemão nascido em 1907 e falecido em 1983.

19 Mais especificamente, Feynman relata em sua palestra que, no artigo de Dirac, era dito que uma função $\mathrm{K}\left(\mathrm{x}, \mathrm{x}^{\prime}\right)$, que leva uma função de onda de um tempo $\mathrm{t}$ a um tempo $\mathrm{t}+\varepsilon$, era análoga à quantia da mecânica clássica calculada a partir da multiplicação de uma exponencial de ie pela função lagrangiana.

${ }^{20}$ Argumentos de simplicidade como este são recorrentes na história da física. Isaac Newton, por exemplo, se baseia em argumentos de simplicidade ao estabelecer suas "Regras do Raciocínio em Filosofia" (NEWTON, 1952) e as utilizou em seus estudos sobre luz e cores (SILVA, 1996).
} 
Além disso, também transparece um aspecto da dimensão conceitual: a busca da simplicidade em construções científicas. Feynman defende que a busca por teorias simples é uma forma aceitável de descobrir fenômenos novos, inclusive recomendando esse tipo de atitude a estudantes iniciantes ${ }^{21}$. Nos últimos parágrafos de sua palestra Feynman reforça sua visão sobre existirem diversas formulações equivalentes das leis da eletrodinâmica e que diferentes teorias podem descrever uma mesma realidade física. Para ele, teorias que são distintas, mas equivalentes em todas as predições, são cientificamente indistinguíveis ( $64^{\circ}$ parágrafo). No mesmo parágrafo, ele diz que é importante que cientistas iniciantes se familiarizem com diferentes formulações de uma mesma teoria para que possam perceber novos aspectos e novos fenômenos, que antes não eram acessíveis devido à existência de poucos pontos de vista.

Feynman comenta, especialmente no $58^{\circ}$ parágrafo, sobre sua preferência em construir um método que seja útil e fácil de ser aplicado, mesmo que não tenha sido matematicamente demonstrado:

Nesse estágio, eu me sentia compelido a publicar isso porque todo mundo dizia que parecia um jeito fácil de fazer cálculos e todos queriam saber como se fazia. Eu precisava publicar, mas faltavam duas coisas: uma era a prova de cada afirmação, no sentido convencional matemático. De vez em quando, mesmo no contexto de um físico, eu não tinha a demonstração de como chegar a todas essas regras e equações a partir da eletrodinâmica convencional. Mas eu sabia, da experiência, de ficar brincando por aí, que tudo aquilo era, de fato, equivalente à eletrodinâmica regular. Eu tinha provas parciais em pedaços, embora eu nunca tivesse realmente sentado, como Euclides ou os geômetras da Grécia e tivesse tido certeza de que eu poderia conseguir tudo aquilo a partir de um simples conjunto de axiomas. Por consequência, o trabalho foi criticado, eu não sei se de maneira favorável ou desfavorável. O "método" foi chamado de "método intuitivo". Áqueles que não percebem isso, no entanto, eu quero ressaltar que há muito trabalho envolvido ao usar esse "método intuitivo" da maneira correta. Pois, já que não há prova simples da fórmula ou das ideias, é necessário fazer um grande número de checagens e revisões para consistência e correção em termos do que é conhecido, comparando-se com outros exemplos análogos, casos limitantes, etc. Em face da falta de demonstração matemática direta, você deve ser cuidadoso e meticuloso para ter certeza do seu ponto e deve também tentar perpetuamente demonstrar o máximo possível da fórmula. Apesar disso, podemos saber muito mais coisas do que podem ser provadas (FEYNMAN, $1965,58^{\circ}$ parágrafo).

Os exemplos acima contradizem visões ingênuas de que os cientistas são sempre guiados pela razão e métodos seguros, que uma teoria física sempre é construída sobre uma sólida base matemática. Este não é o caso do desenvolvimento dos famosos diagramas de

\footnotetext{
${ }^{21}$ O posicionamento de Feynman sobre como os estudantes de ciências devem estudar encontra respaldo em outras comunicações do cientista, sobretudo na famosa passagem dele pelo Brasil, retratada no capítulo "O americano, de novo!” de sua célebre autobiografia O Sr. Está Brincando, Sr. Feynman!
} 
Feynman. As demonstrações rigorosas da validade destes diagramas não eram prioritárias para Feynman, pois ele sentia que tudo estava certo, e, além disso, era uma boa ferramenta para facilitar cálculos.

Sob o ponto de vista da Ciência Integral, as escolhas estéticas refletem aspectos da dimensão conceitual do desenvolvimento do trabalho científico. Por vezes, cientistas se veem na posição de escolher um modo de avançar suas construções teóricas que não necessariamente é pautado pela racionalidade ou meramente pelo que é observado. Há uma preferência, no caso de Feynman, por teorias que, nos termos dele, sejam "elegantes" e que tenham "boa aparência".

\section{V.3 O anedotário Feynmaniano}

Feynman é popular por suas anedotas contadas em suas autobiografias e livros de física. Durante a palestra, Feynman também conta diversas anedotas sobre descobertas e avanços teóricos. Logo nos primeiros dois parágrafos, diz claramente que vai usá-las, mesmo sabendo que não têm qualquer valor científico ou para o entendimento do que realmente ocorreu no desenvolvimento de suas teorias. Elas foram incluídas apenas para que a palestra ficasse mais interessante, segundo o físico.

Ao narrar seus estudos sobre a natureza do pósitron, Feynman insere uma anedota envolvendo seu orientador John Archibald Wheeler, que supostamente lhe telefonara dizendo ter chegado à conclusão de que todos os elétrons do universo seriam o mesmo elétron. Isso, para Wheeler, explicaria o porquê dos elétrons serem indistinguíveis entre si:

Como um subproduto dessa mesma visão, eu recebi um telefonema certo dia na pósgraduação de Princeton do Professor Wheeler, em que ele disse "Feynman, eu sei por que todos os elétrons têm mesma carga e mesma massa". "Por quê?". "Porque eles são todos o mesmo elétron!”. E então ele me explicou pelo telefone: "suponha que as linhas de mundo que estávamos considerando ordinariamente até agora no espaço e no tempo, em vez de irem em frente no tempo, fossem um tremendo nó e então, quando cortamos através do nó, pelo plano correspondente a um plano fixo, veríamos muitas, muitas linhas de mundo. Isso representaria muitos elétrons, exceto por um detalhe: se, em uma seção, essa é uma linha de mundo comum de elétron, na seção em que ela se inverte e está voltando do futuro nós teríamos o sinal errado para o tempo próprio das quadrivelocidades próprias. Isso é equivalente a trocar o sinal da carga, e, portanto, aquela parte da trajetória atuaria como um pósitron". "Mas, Professor", eu disse, "não existem tantos pósitrons quanto elétrons". "Bem, talvez eles estejam escondidos nos prótons ou algo assim”, ele disse. Eu não levei tão a sério a ideia de que todos os elétrons são o mesmo, como levei a observação de que pósitrons poderiam ser representados simplesmente como elétrons indo do futuro para o passado em uma seção inversa de suas linhas de mundo. Isso, eu roubei! (FEYNMAN, 1965, $25^{\circ}$ parágrafo) 
Feynman diz que não aceitou a ideia de que haveria somente um elétron no universo, mas que "roubou" a ideia do pósitron ser enxergado como um elétron vindo do futuro. Feynman dá mais detalhes sobre esse episódio no $54^{\circ}$ parágrafo, quando relata sobre seu trabalho a respeito da energia de interação do elétron com ele próprio:

\begin{abstract}
Mas um passo importante, em que algo fisicamente novo estava envolvido, tinha a ver com o mar de energia negativa de Dirac, que me causou tantas dificuldades lógicas. Eu estive tão confuso que me lembrei da velha ideia de Wheeler sobre o pósitron ser, talvez, o elétron voltando no tempo. Portanto, na teoria de perturbação dependente do tempo que era o usual para se conseguir a auto-energia, simplesmente supus que por um instante nós pudéssemos ir para trás no tempo e olhei quais termos conseguiria ao inverter a ordem temporal das variáveis. Eles eram os mesmos termos que outras pessoas conseguiram quando resolveram o problema de um jeito mais complicado, usando buracos no mar [de energia], exceto, possivelmente, por alguns sinais. Estes, a princípio, eu determinei empiricamente inventando e tentando algumas regras (FEYNMAN, 1965, 54 parágrafo).
\end{abstract}

No trecho final da palestra, no parágrafo 61, Feynman conclui que a ideia da troca temporal entre elétron e pósitron, apesar de útil, não era estritamente necessária para o desenvolvimento teórico:

Isso completa a história do desenvolvimento da visão espaço-temporal da eletrodinâmica quântica. Eu penso se alguma coisa pode ser aprendida disso. Eu duvido. $\boldsymbol{O}$ mais impressionante é que a maior parte das ideias desenvolvidas no decorrer dessa pesquisa não foram usadas no resultado final. Por exemplo, o potencial metade avançado e metade retardado não foi usado no fim, a expressão de ação (1) ${ }^{22}$ não foi usada, e a ideia de que as cargas não atuam sobre si mesmas foi abandonada. A formulação de integrais de trajetória da mecânica quântica foi útil para fazer estimativas nas expressões finais e para formular a teoria geral da eletrodinâmica de maneiras novas - mas ela não foi estritamente necessária. O mesmo vale para ideia de o pósitron ser um elétron movendo-se para trás no tempo, era muito conveniente, mas não estritamente necessário para a teoria porque é exatamente equivalente do ponto de vista do mar de energia negativa (FEYNMAN, 1965, 61º parágrafo).

Portanto, quanto à anedota sobre a natureza dos pósitrons, Feynman comenta que adotou parte da explicação não-convencional de Wheeler sobre a hipótese da existência de um único elétron no universo a fim de interpretar matematicamente a simetria entre a troca do sinal da carga do elétron e a troca do sinal temporal desse elétron. No entanto, a seguir, afirma que essa ideia seria somente mais uma alegoria desnecessária para o desenvolvimento da teoria. É notório, no entanto, que, de acordo com sua descrição, a ideia heterodoxa e até mesmo muito ousada sobre a existência de um só elétron, gerou frutos, ainda que temporários, na construção formal de uma teoria que é atualmente aceita pela comunidade científica.

\footnotetext{
${ }^{22}$ Veja nota 13.
} 
Mesmo ao contar sobre feitos de outros cientistas, Feynman recorre a anedotas. Por exemplo, quando comenta a respeito da importância dos trabalhos de Lamb para a área da eletrodinâmica e como o cientista Hans Bethe solucionou alguns dos problemas por ele apontados, diz que Bethe fez a "mais importante descoberta da história da eletrodinâmica quântica" num trem em Ithaca:

Então Lamb fez seu experimento, medindo a separação dos niveis $2 S_{\frac{1}{2}}$ e $2 P_{\frac{1}{2}}$ do hidrogênio, verificando que era de cerca de 1000 megaciclos de diferença de frequência. O Professor Bethe, com o qual eu era associado à época em Cornell, é um homem que tem essa característica: se há um bom número experimental, você deve achá-lo pela teoria. Então ele forçou a eletrodinâmica quântica daquele tempo a dar uma resposta para a separação desses dois niveis. Ele apontou que a autoenergia do elétron é, por si só, infinita, então a energia calculada de um elétron ligado também deveria ser infinita. Mas, quando você calculava a separação dos dois niveis de energia em termos da massa corrigida em vez da antiga massa, a teoria deveria dar respostas convergentes finitas. Ele fez uma estimativa da separação dessa forma e descobriu que ainda era divergente, mas ele achou que isso era provavelmente pelo fato de que ele havia usado uma teoria não relativistica da matéria. Assumindo que fosse convergente, se relativisticamente tratada, ele estimou que teria cerca de mil megaciclos para o desvio de Lamb, e, então, fez a mais importante descoberta da história da eletrodinâmica quântica. Ele descobriu isso num trem de Ithaca, Nova Iorque, para Schenectady e me telefonou animado de Schenectady para me contar o resultado, o qual eu não me lembro de ter apreciado por completo naquela época (FEYNMAN, 1965, $47^{\circ}$ parágrafo).

A última anedota ocorre no $57^{\circ}$ parágrafo do discurso, quando Feynman relata ter chegado a uma versão muito mais geral de certa formulação matemática do que a que era conhecida à época:

Certo dia, uma disputa emergiu numa reunião da Physical Society, sobre a correção de um cálculo de [Murray] Slotnick sobre a interação de um elétron com um nêutron usando teoria pseudo-escalar com acoplamento de pseudo-vetores, e, além disso, teoria de pseudo-escalar com acoplamento pseudo-escalar. Ele havia descoberto que as respostas não eram as mesmas. Na verdade, por uma teoria, o resultado era divergente, embora convergente pela outra. Algumas pessoas acreditavam que as duas teorias deveriam dar a mesma resposta para o problema. Essa era uma boa oportunidade inicial para eu testar meus achismos sobre ter realmente entendido o que eram esses acoplamentos. Então fui para casa. Durante a tarde trabalhei no espalhamento do elétron e do nêutron para o acoplamento pseudo-escalar e pseudo-vetorial, vi que eles não eram iguais e os subtrai e esmiucei a diferença em detalhes. No dia seguinte, na reunião, eu vi Slotnick e disse "Slotnick, eu trabalhei [neste problema] na noite passada, queria ver se teria as mesmas respostas que você. Eu tive respostas diferentes para cada acoplamento, mas eu queria checar em detalhes com você porque eu quero ter certeza dos meus métodos". Ele disse, então, 
“o que você quer dizer com 'trabalhou noite passada'? Isso me tomou seis meses!", e, quando comparamos as respostas, ele olhou para a minha e perguntou "o que é esse $Q$ aqui, essa variável $Q$ ?” (eu tinha expressões como $\frac{\tan ^{-1} Q}{Q}$, etc). Eu disse "esse é o momentum transferido pelo elétron, o elétron defletido por diferentes ângulos". "Oh”, ele disse, "não, eu só tenho o valor limite quando $Q$ se aproxima de zero; o espalhamento frontal". Bom, foi bem fácil substituir $Q$ por zero na minha forma e então eu tive as mesmas respostas que ele. Mas demorou seis meses para ele fazer o caso da transferência nula de momentum, enquanto que, numa tarde, eu havia resolvido o caso da transferência finita e arbitrária de momentum. Esse foi um grande momento para mim, foi como receber o Prêmio Nobel, porque eu havia me convencido de que, enfim, eu tinha um tipo de método e técnica. Entendia como fazer algo que outras pessoas não sabiam fazer. Esse foi o meu momento de triunfo, em que percebi que eu realmente tinha sucedido em fazer algo que valia a pena (FEYNMAN, 1965, 57º parágrafo).

Feynman considera a descoberta tão importante quanto receber um Prêmio Nobel. Tanto por suas autobiografias, quanto em biografias escritas por terceiros, sabemos que inicialmente Feynman teria pensado até mesmo em recusar o Prêmio, por considerá-lo apenas um evento formal demais, que não combinava com a forma do cientista enxergar as ciências. Em sua visão, esse tipo de compromisso era burocrático, e, já tendo outras premiações científicas, o maior reconhecimento que ele poderia querer seria o legado de inspirar novos cientistas a fazerem seus trabalhos (MEHRA, 1994, p. 573). Além disso, recordemos o contexto em que Feynman havia sido criado, quando, por influência paterna, passou a desenvolver uma relativa aversão a solenidades e a autoridades. É importante recuperar esses fatos ao analisar sua palestra na cerimônia de premiação, pois nos ajuda a compreender os motivos que fizeram o físico a escolher falar sobre aspectos pouco usuais de seu trabalho, enfatizando outros temas.

O uso de anedotas pode ser interpretado como relacionado a duas das dimensões de confiabilidade da Ciência Integral. Por um lado, é relevante analisarmos criticamente essas anedotas a fim de entender um pouco da dimensão conceitual do fazer científico, pois o que elas costumam omitir são informações importantes para que tenhamos uma visão menos ingênua de como a ciência funciona. Os erros, escolhas pessoais e pontos cegos das teorias não devem ser esquecidos, mas analisados à luz do contexto da época e dos cientistas envolvidos. Por outro lado, temos também um reflexo da dimensão sociocultural. Ao fazer relatos por meio de anedotas, Feynman tem a intenção de transmitir uma imagem específica sobre si mesmo e sobre a ciência:a de que os cientistas que fazem trabalhos relevantes para suas áreas tem lampejos de genialidade, de que esses grandes momentos de descoberta podem ser localizados no espaço e no tempo, e também a imagem de que ele próprio lidava com as situações adversas com bom humor e extroversão. 


\title{
V.4 "Feynman porco sexista!"23
}

Desde o início do Prêmio Nobel, em 1901, mais de 900 pessoas foram premiadas pela instituição. No entanto, apenas 54 mulheres, em todos esses anos, foram reconhecidas. Isso não quer dizer que mulheres sejam menos competentes em trabalhos científicos. O que esse fato nos indica, por outro lado, é que existe um viés sexista na escolha de laureados (CHARYTON, ELLIOTT, et al., 2011). Em muitos casos da história da ciência é possível encontrar relatos de que mulheres foram menosprezadas ou silenciadas por cientistas homens. Apesar de ter havido avanços, por exemplo, no número de mulheres que ingressam em carreiras científicas nas últimas décadas, existem ainda diversos fatores sociais e culturais que permanecem diminuindo ou invisibilisando o papel das mulheres na construção científica (SARSEKE, 2017; VICENTE; KILLNER, 2017). A discussão a respeito do viés de gênero nas ciências é extensa e complexa. Neste artigo, pretendemos demonstrar como essa questão aparece no discurso oficial de um cientista renomado e respeitado como Richard Feynman.

Como citado anteriormente, Feynman comparou sua teoria física a uma mulher a qual havia se apegado enquanto jovem ( $8^{\circ}$ parágrafo). Essa comparação é retomada justamente na finalização da palestra:

\begin{abstract}
Então o que aconteceu com a velha teoria com a qual eu me apaixonei quando jovem? Bem, eu diria que ela se tornou uma velha senhora, com pouca atratividade sobrando e os jovens de hoje não sentem mais palpitações no coração quando olham para ela. Mas o que nós podemos dizer de melhor sobre qualquer velha mulher é que ela se tornou uma mãe muito boa e deu à luz alguns bons filhos. E eu agradeço a Academia Sueca de Ciencias por reconhecer um deles. Obrigado (FEYNMAN, 1965, 66 ${ }^{\circ}$ parágrafo).
\end{abstract}

Esses comentários e comparações são esdrúxulos, simplistas, misóginos e desnecessários. No entanto, ecoam algumas das descrições que ele mesmo fazia sobre sua relação com as mulheres. Em suas autobiografias, não é raro encontrar passagens em que relata conflitos com amigas, namoradas e esposas. Feynman fora casado diversas vezes e há rumores de que em um de seus casamentos agrediu fisicamente sua esposa ${ }^{24}$.

As falas machistas de Feynman podem soar até chocantes quando confrontados com visões populares idealizadas de cientistas; no caso, a suposta imagem de um gênio bemhumorado, contrário à visão burocrática e sisuda de alguns cientistas. Entretanto, ilustram

\footnotetext{
${ }^{23}$ O título desta seção é uma referência de algo dito pelo próprio Richard Feynman, em uma de suas autobiografias (FEYNMAN e LEIGHTON, 1988). Naquele contexto, ele comenta sobre uma desavença que teve com um grupo feminista que questionava algumas das formas como ele se comunicava com o público. Portanto, a polêmica sobre algumas colocações machistas e misóginas de Richard Feynman não é novidade. O próprio físico parecia se regozijar com isso.

${ }^{24}$ A investigação de Richard Feynman pelo FBI veio a público em 2012 devido à liberação de alguns documentos por meio do Ato de Liberdade de Informação dos EUA (FOI/PA). Alguns veículos de comunicação fizeram reportagens e exibiram os documentos a respeito dessa questão, por exemplo, o famoso website de divulgação científica Gizmodo (CONDLIFFE, 2012).
} 
bem a dimensão sociocultural da ciência que engloba visões ideológicas sobre temas diversos, inclusive sua visão pessoal a respeito de gênero e suas convicções a respeito do papel das mulheres numa sociedade. Sob a ótica da Ciência Integral, o viés de gênero é um importante aspecto da dimensão sociocultural da confiabilidade científica.

\section{Conclusões}

Richard Feynman é, sem dúvidas, um dos personagens mais representativos da física, sobretudo da física desenvolvida no século XX. Suas contribuições para a física teórica, para a eletrodinâmica quântica e para a física de partículas são consolidadas. Além disso, Feynman pronunciou-se abertamente sobre outros assuntos, como a questão do ensino de ciências, tanto nos EUA quanto na América Latina, sobretudo no Brasil. As estreitas relações que existiram entre Richard Feynman e o Brasil acentuam a relevância dos estudos a respeito do que pensava esse cientista específico, visando a construção de conhecimentos no âmbito do ensino da física no Brasil. Os comentários de alguém tão representativo para as ciências sobre esses temas devem ser considerados e refletidos, pois Feynman é uma celebridade, e isso faz com que suas ideias influenciem cientistas e formadores de opinião.

Uma análise respaldada por estudos de fontes secundárias e registros biográficos da palestra proferida por Feynman, ao receber o Prêmio Nobel, explicita algumas informações que permitem um entendimento mais aprofundado e crítico sobre o que o cientista defendia. Com isso, é possível compreender muitas das visões transmitidas por ele em uma comunicação pública de grande impacto. Mesmo em se tratando de uma comunicação que passou previamente por revisões, filtros e edições pelo cientista, trata-se de uma fonte significativa para investigarmos quais tipos de mensagens e visões Feynman tinha reais intenções de transmitir ao público geral e à História.

Um texto pode ser lido de diferentes maneiras, de acordo com as intencionalidades do leitor a respeito das perguntas a serem respondidas. Resgatando o referencial teórico da Ciência Integral, podemos organizar algumas lições extraídas pela análise da palestra de Feynman utilizando as três dimensões de confiabilidade do conhecimento científico:

- Dimensão observacional: Embora o foco do trabalho de Feynman tenha sido teórico, as relações entre teorias e observações experimentais permeiam o conteúdo da palestra. O cientista conta, no parágrafo 47 , como os experimentos sobre o desvio de Lamb foram influentes ao nortearem as expectativas que Feynman tinha em relação aos resultados que sua teoria deveria prever. Das dimensões de confiabilidade trabalhadas, a observacional é a que fica menos enfatizada pela palestra, dada a natureza do trabalho de Richard Feynman, que se dedicava à física teórica.

- Dimensão conceitual: Nesta, podemos incluir tanto o papel dos erros na construção científica de Feynman, quanto às crenças epistemológicas defendidas pelo cientista. O uso de modelos ( $31^{\circ}$ parágrafo), a criação de diagramas para facilitar cálculos ( $58^{\circ}$ parágrafo) e a crença de que o método de tentativa e erro seria o mais adequado para 
se descobrir novos fenômenos constituem uma mostra representativa sobre algumas ideias que Feynman tinha em relação à parte conceitual de seu trabalho.

- Dimensão sociocultural: O uso recorrente de anedotas constitui um recurso retórico importante para se passar um tipo de imagem específica sobre o trabalho do cientista - e, por consequência, sobre as ciências em geral. Isso constitui, portanto, um aspecto da comunicação do cientista não somente com seus pares, mas com toda a humanidade e com a História (dada a importância do Prêmio Nobel). Também destacamos nesta palestra os comentários machistas do cientista, demonstrando que, apesar de todas as contribuições para a ciência, Feynman não está acima de erros e das opiniões preconceituosas. Pode ser incluída nesta dimensão, ainda, o viés de nacionalidade de Feynman, que, em uma das anedotas, compara o modo de trabalho dos cientistas norte-americanos ao dos cientistas europeus.

A palestra de Feynman fornece, ainda, informações sobre algumas visões controversas defendidas pelo cientista. Ao tecer comentários de cunho machista, podemos ponderar sobre como os cientistas muitas vezes são retratados em materiais de divulgação científica. Nenhum cientista está isolado de seu contexto ou de sua época e de sua cultura ou seus costumes. A construção científica é muito mais ampla e complexa do que as simplificações e mitificações frequentemente realizadas. Distorções, muito mais que simplesmente indesejadas, são nocivas ao entendimento público sobre as ciências. Uma compreensão crítica sobre as ciências e sobre as atitudes dos cientistas em relação ao mundo e à sociedade são de suma importância para que possamos entender melhor qual a importância de se desenvolverem pesquisas científicas numa sociedade moderna. Feynman ter feito comparações sexistas entre mulheres e teorias físicas não torna seus trabalhos em eletrodinâmica menos valorosos, mas inegavelmente abre caminho para uma nova camada de considerações quando pensamos sobre a persona de Richard Feynman. Com o olhar atual, em que estão cada vez mais em voga os debates sobre o papel das mulheres nas ciências e as desigualdades causadas pelo viés de gênero nas instituições científicas e sociedade em geral, ler a palestra de Feynman pode incentivar discussões sobre o que mudou desde 1965 e o que não mudou nesse aspecto.

O tipo de análise aqui apresentada não é o único possível. Outras abordagens podem ser realizadas, e, ao se analisarem as mesmas fontes, podem ser extraídas conclusões diferentes. Acreditamos que essas palestras oficiais podem ser bastante relevantes para entendermos diversos aspectos de como a ciência passou por transformações e evoluções ao longo do século XX.

Além de aspectos conceituais e cognitivos, é possível explorar em sala de aula conhecimentos referentes ao contexto sociocultural em que ocorreu algum avanço científico, sobre os processos de validação de novos conhecimentos produzidos e quais possíveis interesses ou crenças estavam em jogo. A palestra de Feynman abre diversos caminhos para discussões em sala de aula. Por exemplo: posicionamentos machistas de cientistas ainda ocorrem? Em que medida esse aspecto mudou desde 1965? Em que medida permanece parecido? Outra 
questão que pode ser trabalhada a partir dessa análise é: quando nos deparamos com relatos em livros-textos ou materiais de divulgação científica, é possível termos "dicas" de quais aspectos podem ter sido distorcidos em prol de uma narrativa mais interessante ao público? Quais são as perdas conceituais desse tipo de distorção? Em que medida os próprios cientistas fomentam, por vezes, essas descrições anedóticas? Quais são os interesses envolvidos?

Utilizando-se uma abordagem histórica a respeito da natureza da ciência, existem diversas ferramentas possíveis para a prática em sala de aula, por exemplo, júris simulados, debates mediados, sequências didáticas, dentre outros. Nossa intenção com o presente trabalho não é indicar um modo específico de trabalhar essas questões em aula, mas apresentar subsídios para que essas discussões possam ocorrer, usando o referencial da Ciência Integral. Ao realçarmos as dimensões observacionais, conceituais e socioculturais do fazer científico, temos um ferramental teórico relevante para um entendimento crítico de como a ciência funciona e quais são seus agentes e interesses. O mesmo tipo de análise que fizemos da palestra de Feynman pode ser estendido até mesmo a outros materiais oriundos de fontes primárias, de outros cientistas de diferentes épocas e contextos, não se limitando somente aos estudos das palestras do Nobel.

A discussão de questões sobre a natureza da ciência em sala de aula ameniza algumas ideias ingênuas sobre as ciências, por exemplo, a de que a ciência é neutra, ou que os cientistas seguem sempre um mesmo método, guiados somente pela razão e pela lógica. Além disso, nos afastamos da imagem pasteurizada da ciência e dos cientistas. Numa época marcada por muitos questionamentos, às vezes exagerados e mal informados, sobre as ciências, apresentar uma visão contextualizada, pautada em fontes históricas e críticas é necessário. A partir de estudos deste tipo, é possível fomentar, aludindo ao referencial da Ciência Integral, visões menos "ultraprocessadas" da ciência. Erros, controvérsias, idas e vindas, escolhas pessoais e crenças dos agentes científicos não devem ser apagados, mas lidos de acordo com o contexto. Assim, apesar de todos esses aspectos, a ciência constitui um campo confiável de conhecimento, capaz de trazer novos olhares sobre o mundo, com influências tanto diretas, como a criação de novas tecnologias, quanto indiretas, por exemplo, visões a respeito da realidade e da natureza.

\section{Agradecimentos}

Agradecemos ao Conselho Nacional de Desenvolvimento Científico e Tecnológico (CNPq), processo no 309910/2015-3 pela Bolsa de Produtividade em Pesquisa, à CAPES pela Bolsa de Mestrado e aos pareceristas pelos comentários. 


\section{Referências}

ALLCHIN, D. The Nature of Science: From Test Tubes to YouTube. In: ALLCHIN, D. Teaching the Nature of Science: Perspectives \& Resources. Saint Paul: SHiPS Education Press, 2013. Cap. 1, p. 3-27.

BARDIN, L. Análise de Conteúdo. Lisboa: Edições 70, 1977.

BASSALO, J. M. F.; JUNIOR, O. F. Wheeler, Tiomno e a Física Brasileira. Revista Brasileira de Ensino de Física, v. 25, n. 4, p. 426-437, dez. 2003.

BLACKBURN, S. Rationalism. In: BLACKBURN, S. The Oxford Dictionary of Philosophy. Oxford: Oxford University Press, 1996. p. 318-319.

BLANSHARD, B. Rationalism. Encyclopædia Britannica, London, 22 Jul 2016. Disponivel em: $<$ https://www.britannica.com/topic/rationalism>. Acesso em: 27 nov. 2019.

BROWN, L. M. Selected Papers of Richard Feynman with Commentary. River Edge: World Scientific Publishing, 2000.

CHARYTON, C. et al. Gender and science: Women Nobel laureates. The journal of creative behavior, v. 45, n. 3, p. 203-214, 2011.

CONDLIFFE, J. Richard Feynman's FBI Files Make Fascinating Reading. Gizmodo, 7 Agosto 2012. Disponivel em: <https:/gizmodo.com/richard-feynmans-fbi-files-makefascinating-reading-5916502>. Acesso em: 3 abr. 2019.

DYSON, F. J. The electromagnetic shift of energy levels. Physical Review, v. 73, p. 617, mar. 1948.

DYSON, F. J. The radiation theories of Tomonaga, Schwinger and Feynman. Physical Review, v. 75, p. 486, fev. 1949.

FEYNMAN, R. P. Space-time approach to non-relativistic quantum mechanics. Reviews of modern physics, v. 20, n. 2, p. 367-387, 1948.

FEYNMAN, R. P. An operator calculus having applications in quantum electrodynamics.

Physical Review, v. 84, n. 1, p. 108-128, 1951. 
FEYNMAN, R. P. QED - The Strange Theory of Light and Matter. Princeton: Princeton University Press, 1985.

FEYNMAN, R. P. O senhor está brincando, Sr. Feynman!: as estranhas aventuras de um físico excêntrico (Trad. Alexandre C. Tort). Rio de Janeiro: Elsevier, 2006.

FEYNMAN, R. P.; LEIGHTON, R. Is electricity fire? In: FEYNMAN, R. P.; LEIGHTON, R. "Surely you're joking, Mr. Feynman!": Adventures of a curious character. New York: W. W. Norton, 1985.

FEYNMAN, R. P.; LEIGHTON, R. Feynman Sexist Pig! In: FEYNMAN, R. P.; LEIGHTON, R. What do you care what other people think? Further adventures of a Curious Character. New York: Bantam Books, 1988. p. 72-75.

FEYNMAN, R. P.; LEIGHTON, R. What do you care what other people think?: Further adventures of a curious character. New York: Norton, 1988.

GLEICK, J. Genius: the life and science of Richard Feynman. New York: Vintage Books, 1993.

GOLINSKI, J. V. Language, Discourse and Science. In: OLBY, R. C. et al. Companion to the history of modern science. London \& New York: Princeton University Press, 1990. Cap. 9, p. 110-126.

GRIFFITHS, D. The Feynman Calculus. In: GRIFFITHS, D. Introduction to Elementary Particles. 2. ed. Weinheim: Wiley-VCH Verlag GmbH, 2008. Cap. 6, p. 197-225.

JACKSON, J. D. Retarded solutions for the Fields: Jefimenko's Generalizations of the Coulomb and Biot-Savart Laws; Heaviside-Feynman Epressions for Fields of Point Charge. In: JACKSON, J. D. Classical Electrodynamics. 3. ed. Hoboken: John Wiley \& Sons, 1999. Cap. 6.5, p. 246-247.

KRAGH, H. Scientists' histories. In: KRAGH, H. An introduction to the historiography of science. New York: Cambridge University Press, 1987. Cap. 13, p. 150-158.

KRAGH, H. Fundamental Theories. In: KRAGH, H. Quantum Generations: a History of Physics in the Twentieth Century. Princeton: Princeton University Press, 2002. Cap. 22, p. 332-48. 
KRAGH, H. Nobel Physics. In: KRAGH, H. Quantum Generations: A history of Physics in the Twentieth Century. Princeton: Princeton University Press, 2002. Cap. 28, p. 427-39.

LICIO, J. G. Prêmio Nobel: palestras oficiais sob a perspectiva da ciência integral 2018. Dissertação (Mestrado) - Universidade de São Paulo, Faculdade de Educação, Instituto de Física, Instituto de Química e Instituto de Biociências.

MARTINS, R. D. A. A maçã de Newton: história, lendas e tolices. In: SILVA, C. C. Estudos de história e filosofia das ciências: subsídios para aplicação no ensino. São Paulo: Editora Livraria da Física, 2006. Cap. IX, p. 167-189.

MATTHEWS, M. R. History of Science in the Curriculum. In: MATTHEWS, M. R. Science Teaching: The role of History and Philosophy of Science. New York - London: Routledge, 1994. Cap. 4, p. 49-82.

MEHRA, J. The beat of a different drum: the life and science of Richard Feynman. Oxford: Oxford University Press, 1994.

MLODINOW, L. Feynman's Rainbow: A search for beauty in physics and life. New York: Vintage Books, 2011.

MORAES, R.; GALIAZZI, M. D. C. Análise Textual Discursiva: Análise de conteúdo? Análise de discurso? In: MORAES, R.; GALIAZZI, M. D. C. Análise Textual Discursiva. 3. ed. Ijuí: Editora Unijuí, 2016. Cap. 6, p. 161-84.

NEWTON, I. Mathematical Principles of Natural Philosophy. In: MOTTE, A.; CAJORI, F. Great Books of the Western World. Chicago/London/Toronto: Encyclopaedia Britannica, v. 34, 1952. p. $270-271$.

NOBELPRIZE.ORG. The Nobel Prize in Physics 1965. The Nobel Prize, 2019. Disponivel em: <https://www.nobelprize.org/prizes/physics/1965/summary/>. Acesso em: 02 dez. 2019.

NOVAES, M. A eletrodinâmica quântica de Feynman - tradução de sua palestra Nobel. Revista Brasileira de Ensino de Física, São Paulo, v. 40, n. 4, p. e4209, 2018. OTTAVIANI, J.; MYRICK, L. Feynman. New York: First Second Books, 2011.

RILEY, K. F.; HOBSON, M. P.; BENCE, S. J. Eigenvectors and Eigenvalues. In: RILEY, K. F.; HOBSON, M. P.; BENCE, S. J. Mathematical Methods for Physics and Engineering. 3. ed. Cambridge: Cambridge University Press, 2006. Cap. 8.13, p. 272-279. 
ROBERTS, D. A. What counts as science education. In: FENSHAM, P. Development and Dilemmas in Science Education. Bristol: Taylor \& Francis, 1988. Cap. 2, p. 27-54.

ROBINSON, J. T. Science Teaching and the Nature of Science. Journal of Research in Science Teaching, v. 3, 1965. p. 37-50.

SAKURAI, J. J. Feynman's space-time approach to electron propagator. In: SAKURAI, J. H. Advanced Quantum Mechanics. Boston: Addison-Wesley, 1967. Cap. 4-5, p. 231-241.

SANTOS, W. L. P. D.; MORTIMER, E. F. Uma análise de pressupostos teóricos da abordagem C-T-S (Ciência-Tecnologia-Sociedade) no contexto da educação brasileira. ENSAIO - Pesquisa em Educação de Ciências, Belo Horizonte, v. 2, n. 2, p. 110-132, juldez. 2000.

SARSEKE, G. Under-Representation of Women in Science: From Educational, Feminist and Scientific Views. NASPA Journal About Women in Higher Education, v. 11, n. 1, p. 89$101,2017$.

SCHWEBER, S. S. QED and the men who made it: Dyson, Feynman, Schwinger and Tomonaga. Princeton, New Jersey: Priceton University Press, 1994.

SHANKAR, R. The path integral formulation of quantum theory. In: SHANKAR, R. Principles of Quantum Mechanics. 2. ed. New York: Plenum Press, 1994. Cap. 8, p. 223236.

SHAPIN, S.; SCHAFFER, S. Leviathan and the Air-Pump: Hobbes, Boyle and the Experimental Life. Princeton: Princeton University Press, 1985.

SILVA, C. C. A teoria das cores de Newton: um estudo crítico do Livro I do Opticks 1996. Dissertação (Mestrado) - Instituto de Física Gleb Wataghin, Campinas.

TOMONAGA, S.-I.; OPPENHEIMER, J. On Infinite Field Reactions in Quantum Field Theory. Physical Review, v. 74, n. 2, p. 224-225, 1948.

VICENTE, V. D. C.; KILLNER, G. I. As representações de gênero nas questões de ciências da natureza do ENEM 2015. Seminário Internacional Fazendo Gênero 11 \& 13th Women's Worlds Congress. Florianópolis, p. 1-12, 2017. ISSN ISSN 2179-510X. Anais... 